ARTIGOS 


\title{
Florestan Fernandes e Guerreiro Ramos na CONSTRUÇÃo DE UMA IDÉIA DE BRASIL MODERNO
}

\author{
Tatiana Martins ${ }^{*}$
}

Resumo: Este trabalho tem como objetivo demonstrar a maneira pela qual dois sociólogos brasileiros, Florestan Fernandes e Guerreiro Ramos, nos anos 50 e início dos 60, construíram duas concepções de Brasil Moderno através de seus pressupostos teóricos entendidos como forma de edificação de uma Sociologia Brasileira. Dessa forma, o trabalho busca associar essa tentativa de construção das fundações de uma Sociologia Brasileira com o próprio processo de desenvolvimento nacional e, principalmente, com a formulação de um Projeto Nacional.

Palavras-chave: Florestan Fernandes, Guerreiro Ramos, sociologia brasileira, desenvolvimento nacional.

No emaranhado dos desafios que compõem e decompõem o Brasil como nação, as produções científicas, filosóficas $e$ artísticas podem revelar muito mais o imaginário do que a história, muito menos a nação real do que a ilusória. Mas não bá dúvida de que a história seria irreconhecivel sem o imaginário. Alguns segredos da sociedade se revelam melhor precisamente na forma pela qual ela aparece na fantasia. As vezes, a fantasia pode ser um momento superior da sociedade'.

\section{Delineando uma problemática}

Como destaca Octávio Ianni, a reflexão sobre os limites e as possibilidades da modernidade brasileira é uma constante da história do

\footnotetext{
Doutoranda em Sociologia - IFCH/Unicamp.

${ }^{1}$ IANNI, 2004.
} 
pensamento brasileiro. São várias formas de enfrentamento da questão nacional, temática essa que se tornaria verdadeiro "fascínio" da intelectualidade brasileira cujo ápice se expressaria nos principais momentos de crise estrutural, tais como, a Abolição da Escravatura, a Proclamação da República e, em especial, a Revolução de 30 a partir da qual teriam se constituído as "matrizes do pensamento social brasileiro". As transformações econômicas, políticas, sociais e culturais ocorridas na década de 50 - como o avanço industrial, o papel interventor do Estado na economia e a intensificação da urbanização e do cosmopolitismo tornaram a realização do Brasil como uma nação moderna, aos olhos de vários setores da sociedade, uma possibilidade concreta. O "fascínio", agora, se

estendia a formas de expressão que iam desde os ideários de consumo até os investimentos públicos no desenvolvimento industrial brasileiro. Em todos esses casos, os países representantes do capitalismo desenvolvido ou da civilização moderna ocidental tornam-se os referenciais a

partir dos quais se definiam indagações, necessidades e aspirações. Já no limiar dos anos 60, com o balanço dos resultados do projeto de desenvolvimento nacional de Juscelino Kubitscheck e das crises econômica, política e social emergentes recolocam-se reflexões e projetos, mas tendo, sempre, em vista o desenvolvimento brasileiro mesmo que definido a partir de critérios distintos ${ }^{2}$.

No âmbito do pensamento social brasileiro as reflexões sobre os rumos do desenvolvimento nacional intensificam-se na medida daquelas transformações e, por essa natureza, não podem fugir, de uma maneira ou de outra, da reflexão sobre os referenciais internacionais que

${ }^{2}$ Para maior detalhamento sobre as tensões sociais e políticas e sobre o esgotamento da economia brasileira no período e sobre as novas formas de sociabilidade, consultar: IANNI, Octavio. O colapso do populismo no Brasil. 3a. edição, Rio de Janeiro: Civilização Brasileira, 1975; LESSA, Carlos. 15 anos de política econômica. São Paulo: Brasiliense, 1981; MELLO, João Manuel Cardoso de. "Capitalismo Tardio e Sociabilidade Moderna". In: SCHWARCZ, Lilia Moritz (org.) História da Vida Privada no Brasil. Contrastes da intimidade contemporânea. São Paulo: Companhia das Letras, v.4, 1998; ARRUDA, Maria Arminda do Nascimento. Metrópole e Cultura: São Paulo no meio do século XX. Bauru, SP: EDUSC, 2001. 
constituem uma idéia de Brasil moderno. No decorrer dos anos 50 e início dos anos 60, a tônica das discussões sobre o desenvolvimento nacional envolve constantemente as possibilidades de um projeto de duas faces geradoras de uma tensão fundamental: aquela que definia as tendências do país tornar-se uma nação desenvolvida (e, que, considerando as diferenças de abordagens, pressupunha a dimensão universalista dos projetos) e, outra, que se deparava com as particularidades históricas que colocavam a especificidade do processo de desenvolvimento no Brasil. É com essas indagações que dois sociólogos brasileiros, Florestan Fernandes e Guerreiro Ramos, têm de lidar quando propõem a construção de uma Sociologia Brasileira em plena associação com o processo de emergência do Brasil moderno, ou desenvolvido.

Para ambos os autores, dentre as transformações ocorridas no Brasil a partir de 45 no sentido da modernização brasileira, figura a necessidade de fundação de uma Sociologia Nacional que não apenas representasse o ritmo da disciplina em relação ao processo de desenvolvimento nacional, mas que, principalmente, contribuísse para a plena realização do mesmo. Essa percepção comum, entretanto, não foi suficiente para gerar os mesmos resultados. Fatores diversos concorrem tanto para a aproximação quanto para a diferenciação das análises efetivadas pelos sociólogos. Para além dessa primeira aproximação que os destina à tarefa de edificação da Sociologia Brasileira a partir de certa visão da

realidade nacional, pode-se diferenciar suas interpretações tendo em vista, por exemplo, a trajetória intelectual ou as instituições nas quais Florestan Fernandes e Guerreiro Ramos atuaram. Nesse caso, a partir da vinculação dos trabalhos do primeiro $^{3}$ aos princípios a que se destinava a

\footnotetext{
${ }^{3}$ Florestan Fernandes ingressou no curso de Ciências Sociais da FFCL da USP em 1941, graduando-se em 1944. Após a realização de seu mestrado na Escola Livre de Sociologia e Política na qual obtém o título em 1947 com o trabalho A Organização Social dos Tupinambá, defende na USP a tese de doutorado A Função Social da Guerra na Sociedade Tupinambá em 1951, a tese de livre-docência na cadeira de Sociologia I Ensaio sobre o Método de Interpretação Funcionalista em 1953 e a tese de cátedra A Integração do Negro na Sociedade de Classes em 1964. Atuou como professor nessa universidade até o ano de 1969, quando foi cassado pelo regime militar. Para uma análise do processo de formação intelectual de Florestan Fernandes, consultar: GAR-
} 
vida acadêmica na FFCL da Universidade de São Paulo e os do segundo ${ }^{4}$ ao caráter político das instituições nas quais trabalhou, é possível se chegar a uma caracterização dessa produção baseada numa polarização entre Ciência e Política, nas quais tais dimensões aparecem enquanto campos autônomos. Dessa forma, a dimensão política se restringe a lutas internas pelo poder, ou legitimidade, no campo. Ainda na perspectiva institucional seria possível definir a dimensão política à participação na vida política institucional, ou seja, no governo ou a órgãos diretamente ligados a ele. Nesse sentido, a política também acaba confinada às disputas político-ideológicas no aparelho governamental. Contudo, outra forma de politização da produção do conhecimento pode ser apreendida a partir da tomada dessas idéias como forças sociais, ou seja, enquanto expressão das tensões sociais. Apresentando determinadas formas de apreensão da realidade, ou determinada visão do mundo, a produção do conhecimento adquire caráter político uma vez que essas formas podem ser compreendidas como fundamento da formulação de projetos. Em se tratando

CIA, Sylvia Gemignani. (2002) Destino impar: sobre a formação de Florestan Fernandes. São Paulo, USP, Editora 34.

${ }^{4}$ Em sua juventude na Bahia, Guerreiro Ramos trabalhou na Administração de Landulfo Alves, teve formação católica, ingressou e se desligou do Movimento Integralista e participou da fundação da Faculdade de Filosofia da Bahia, conseguindo, com isso, a cátedra de Ciências Sociais antes mesmo de ingressar num curso nessa área. Isso somente acontece após sua ida ao Rio de Janeiro por intermédio de uma bolsa concedida pelo governo da Bahia. Formou-se em 42 em Ciências Sociais e em 43 em Direito (OLIVEIRA, 1995). Em seguida ministrou um curso no Departamento da Criança, trabalhou no DASP (Departamento Administrativo do Serviço Público - órgão de Administração Pública Federal), na Casa Civil (órgão de assessoramento do Governo Getúlio Vargas) e na EBAP (Escola Brasileira de Administração Pública). Foi um dos fundadores do IBESP (Instituto Brasileiro de Economia, Sociologia e Política) e do ISEB (Instituto Superior de Estudos Brasileiros) - instituições ligadas ao Ministério da Educação criadas com a intenção de constituir uma fonte de pensamento e pesquisas de assessoramento ao governo, sendo que a segunda, que teve na primeira seu embrião, foi extinta em 1964 (TOLEDO, 1997). Faziam parte do grupo que compunha o IBESP e depois o ISEB, alguns integrantes da Casa Civil que já realizariam atividades de assessoramento ao governo (SOARES, 1993) - de onde sai em 1958 ingressando, logo em seguida, na vida política ao candidatar-se em 1962 a deputado federal pelo PTB e ingressar como suplente em 1963. Teve seu mandato casado em 1964, indo, então, para os Estados Unidos onde lecionou e residiu até sua morte em 1982.

Temáticas, Campinas, 14(27/28):157-185, jan./dez. 2006 
especificamente da Sociologia, a forma de apreensão da realidade social, ou a escolha do objeto e do método de investigação, no caso, para a análise da realidade brasileira, podem expressar, a partir desse ponto de vista, determinada concepção de futuro do país, ou projeto de desenvolvimento para o país. As propostas de construção da Sociologia Brasileira e as concepções de desenvolvimento nacional de Florestan Fernandes e Guerreiro Ramos, dessa forma, podem ser politizadas de três maneiras: a) a partir da compreensão das análises enquanto enfrentamento da questão nacional brasileira naquele momento (e, assim, enquanto posicionamentos políticos com relação ao processo de desenvolvimento capitalista e de uma sociedade moderna no Brasil); b) a partir da distinção entre as duas formulações em função dos respectivos projetos de desenvolvimento nacional; c) a partir da definição política de suas formulações em relação a produção de autores contemporâneos. É à discussão dos dois primeiros que este trabalho está direcionado.

\section{UM PROJETO PARA A SOCIOlogia, UM PROJETO PARA O BRASIL}

Partindo, agora, para a construção analítica propriamente dita feita pelos autores, o que chama atenção, em primeiro lugar, é a já destacada compreensão da emergência da Sociologia Brasileira como uma necessidade social do Brasil dos anos 50. Ao mesmo tempo em que tal emergência representa, para ambos os autores um processo de "autoconsciência científica da sociedade" ela é compreendida como catalisadora do desenvolvimento nacional. Esse ponto de vista diz respeito a determinada concepção do papel a ser assumido pela sociologia na sociedade, formulada pelos dois sociólogos, que associa a disciplina ao processo de desenvolvimento

nacional. Além disso, essa perspectiva pressupõe determinada visão sobre o desenvolvimento do pensamento social brasileiro até os anos 50 que aponta para um dos fatores fundamentais de distinção dos moldes definidos pelos autores para a edificação de uma Sociologia Brasileira.

Florestan Fernandes reconhece a partir dos anos 20 e, em especial nos anos 30, o momento de emergência do que admite como padrão de 
trabalho cientifico ${ }^{5}$. Os fatores identificados por ele como condicionantes desse avanço no pensamento sociológico brasileiro consistem na intensificação do que considera como processos de secularização e de racionalização e o desenvolvimento de um suporte institucional para o ensino e a pesquisa. De forma mais específica, para ele, constituem fatores de

emergência da Sociologia Brasileira o surgimento da investigação positiva e a introdução sistemática da pesquisa de campo. No processo de desenvolvimento da disciplina, contudo, Florestan Fernandes compreende que chegados os anos 50, ao mesmo tempo em que se poderia observar tendências de um desenvolvimento autônomo do conhecimento sociológico expressas na formação das primeiras gerações de sociólogos e na crescente valorização do uso da sociologia na sociedade, seria possível encontrar obstáculos para a plena utilização da capacidade reconstrutora da disciplina para as novas necessidades emergentes no âmbito social.

$\mathrm{Na}$ análise do processo de desenvolvimento da Sociologia no Brasil, Guerreiro Ramos identifica duas correntes de pensamento, uma que precisaria ser superada e outra que deveria ser resgatada. A primeira corrente de pensamento sociológico Guerreiro Ramos chama de "consular", em O processo da sociologia no Brasil (1953) e, também, de "enlatada" em Cartilha brasileira do aprendiz de sociólogo $(1954)^{6}$ e a caracteriza pelo que considera como a utilização indiscriminada de teses e autores estrangeiros e, com isso, pelo alheamento em relação à especificidade nacional e aos problemas colocados por ela. Em oposição a esse tipo de atitude, Guerreiro Ramos define uma tradição de pensamento estreitamente vinculada aos problemas da sociedade brasileira, ou seja, uma visão pragmática que seria imanente ao

\footnotetext{
${ }^{5}$ No rol dos precursores da investigação positiva no Brasil Florestan Fernandes coloca Oliveira Vianna, Gilberto Freyre, Caio Prado Júnior, Fernando de Azevedo, Sergio Buarque de Holanda e Nelson Werneck Sodré (FERNANDES, 1980)

${ }^{6}$ Nessa primeira corrente, o sociólogo incorpora os autores Tobias Barreto, Pontes de Miranda, Tristão de Ataíde, Pinto Ferreira e Mário Lins e, num sub-ramo dessa corrente, agrupa Nina Rodrigues, Gilberto Freyre e Arthur Ramos.
} 
conhecimento sociológico ${ }^{7}$. Essa seria, para ele, a atitude capaz de produzir uma "Sociologia Autêntica", ou seja, uma sociologia que enquanto "autoconsciência científica da sociedade" exerceria sua função de reconstrução social. Dito de outra forma, os critérios de objetividade delimitados pelo autor correspondem à capacidade da sociologia em responder às exigências colocadas pela sociedade na qual está inserida e à consciência que a disciplina deveria ter sobre o seu lugar nas tendências dominantes na sociedade.

Como se pode notar, há uma divergência importante entre os dois autores na concepção dos critérios de objetividade na sociologia em relação às raízes do pensamento sociológico brasileiro. Para Florestan Fernandes, esses critérios são definidos a partir dos resultados obtidos com a incorporação dos padrões universais da ciência no Brasil. Por isso,

identifica nos anos 20 e 30 algumas tentativas nesse sentido e nos anos 50 o surgimento dos primeiros resultados da formação de sociólogos nos centros universitários brasileiros. É exatamente esse o ponto de divergência encontrado na argumentação de Guerreiro Ramos. Para ele o que define a emergência da Sociologia nacional não é a utilização desses padrões, mas a vinculação entre a produção do conhecimento e os problemas colocados pela sociedade. A distância entre tais pontos de vista pode ser exemplificada pelo debate travado por Florestan Fernandes e Guerreiro Ramos no final dos anos $50^{8}$.

É a partir da compreensão da maneira pela qual os dois autores definem os instrumentos de análise e de intervenção da sociologia na sociedade que se expressam as raízes de suas concepções de objetividade e de possibilidades de aplicação do conhecimento científico - que como se pôde perceber está diretamente relacionado à maneira pela qual os

\footnotetext{
7 Seriam representantes dessa corrente Silvio Romero, Euclides da Cunha, Alberto Torres e Oliveira Vianna.

${ }^{8}$ O debate pode ser observado em: RAMOS, 1963; FERNANDES, 1976. Para maior detalhamento desse debate e da participação de outros autores no mesmo consultar: BARIANI JR, Edison. A sociologia no Brasil: uma batalha, duas trajetórias (Florestan Fernandes e Guerreiro Ramos). Araraquara, 2003. Dissertação de Mestrado, FCL-UNESP.
} 
sociólogos procuram assimilar a Sociologia produzida nos países avançados. Para Florestan Fernandes, a absorção do conhecimento científico produzido nos países avançados é uma via de mão dupla. Tendo em vista o caráter incipiente da sociologia no Brasil e as dificuldades de expansão da pesquisa científica no país, o sociólogo compreende a incorporação daquele conhecimento como fundamental para a compreensão da realidade nacional, uma vez que daria suporte instrumental para tal realização. Por outro lado, através da utilização de tais recursos, o conhecimento sociológico produzido no Brasil poderia contribuir para a teoria sociológica geral. Isso porque os resultados obtidos em pesquisas realizadas no Brasil, ou em outros países subdesenvolvidos, corresponderiam a generalizações induzidas de uma situação distinta.

Procurando apreender os métodos clássicos de investigação na sociologia, Florestan Fernandes destaca um deles como o fundamental para a interpretação da realidade social brasileira naquele momento: o Método de Interpretação Funcionalista. Essa escolha se justifica, em primeiro lugar, pela atribuição de capacidade analítica do método sobre os processos de mudança social e, dessa forma, sobre o que o autor considera como os processos pelos quais o país estaria passando naquele momento. Em segundo lugar, nas palavras do sociólogo paulista, o método poderia desempenhar funções específicas na sociedade, sobretudo contribuições ao processo de desenvolvimento nacional sendo, dessa forma, o instrumento da Sociologia Aplicada ${ }^{9}$. Além disso, para análise do processo de mudança social brasileiro, o autor destaca a Sociologia Comparada como suporte fundamental por lidar com as características estruturais e funcionais comuns aos sistemas sociais, ou os

\footnotetext{
${ }^{9}$ Como forma de intervenção da ciência na realidade social, esse ramo da Sociologia, para o autor, seria aquele que, face às exigências do processo de desenvolvimento brasileiro, poderia ditar as possibilidades de reconstrução social no sentido da expansão dos valores modernos. Nesse aspecto o método de interpretação funcionalista poderia contribuir para a identificação dos "problemas sociais" em termos de desajustamentos em relação à ordem social e para a definição das soluções a partir do reconhecimento das tendências de desenvolvimento presentes na realidade social, que, naquele momento, deveriam estar direcionados ao âmbito cultural e comportamental.
} 
principia media que, em sua argumentação, seriam, da mesma forma, comuns a sociedades do mesmo tipo. Contudo, a eficiência do papel da Sociologia na

sociedade dependeria, para o sociólogo, da criação de formas de veiculação desse conhecimento produzido para os quais ainda não se encontrariam parâmetros sequer nas sociedades desenvolvidas, pois pressupunha uma nova situação social na qual a idéia de planejamento democrático fosse incorporada na própria organização social.

A partir dessa visão acerca da abrangência do método de interpretação funcionalista, Florestan Fernandes apreende o processo de mudança social brasileiro do ponto de vista cultural e comportamental, ou seja, tomando como base as alterações na esfera de valores que teriam implicações na estrutura social como um todo. Assim, o processo de mudança social brasileiro é entendido enquanto passagem da Ordem Social Tradicional para a Ordem Social Capitalista. O que caracteriza essa transformação, nas palavras do autor, é o desenvolvimento de padrões de comportamento definidos por ele como "racionais". Por isso, a análise tem como referencial os processos de secularização e racionalização ocorridos na Europa (Weber, 1996). É a partir desses parâmetros que reconhece a existência de obstáculos ${ }^{10}$ e de tendências de desenvolvimento.

Em contrapartida, Guerreiro Ramos procura enfatizar a particularidade do processo de desenvolvimento brasileiro e justificar a definição de medidas de desenvolvimento adequadas à situação nacional através do que define como Método Faseológico. Para o sociólogo, esse método consiste na definição da fase de uma sociedade a partir dos principia media nela atuantes, ou seja, a compreensão, tal como Mannheim(1962) definira, das leis que regeriam a organização da sociedade. Se, em Florestan Fernandes essa concepção fora utilizada na análise das leis estruturais que identificavam as sociedades entre si, para

\footnotetext{
${ }^{10}$ Apesar de compreender os condicionantes históricos dos obstáculos ao desenvolvimento nacional, Florestan Fernandes reconhece que o diagnóstico dos "problemas sociais" e a definição de suas soluções teriam melhores resultados se analisados a partir do Método de Interpretação Funcionalista.
} 
Guerreiro Ramos esse era um critério de distinção ${ }^{11}$. Esse é um ponto chave na definição dos "problemas sociais" e de suas "soluções", pois, Florestan Fernandes concebe os parâmetros da Moderna Civilização Ocidental como fundamentais chegando até mesmo a propor soluções sequer concretizadas pelos países desenvolvidos, como é o caso do desempenho da Sociologia na organização democrática da sociedade.

Para Guerreiro Ramos, os "problemas sociais" corresponderiam à fase de desenvolvimento do país, de forma que as "soluções" deveriam ser encontradas nessa situação. A partir daí, esse autor rejeita a definição de "problema social" a partir de critérios estrangeiros, argumentando que somente poderiam ser reconhecidos enquanto tais no momento que o Brasil passasse para uma fase de desenvolvimento superior. Assim, a particularidade da fase de subdesenvolvimento nacional, somente seria superada a partir de uma mudança estrutural na sociedade que ocorreria na medida do desenvolvimento econômico do país ${ }^{12}$. Essa preocupação com a particularidade da situação nacional, com a fase de desenvolvimento do país, dá o tom de grande parte das recomendações que Guerreiro Ramos propõe em Cartilha Brasileira do Aprendiz de Sociólogo (1954). Elas gravitam em torno das necessidades de vinculação prática do conhecimento

\footnotetext{
11 Por outro lado, nos anos 40, a definição de fase estava ligada a uma visão universalista do autor a ponto de a planificação ser compreendida como a nova fase da sociedade ocidental. Da mesma forma, o sociólogo define o livro de Mário Lins A transformação da lógica conceitual da sociologia e a racionalização da administração pública brasileira como expressão de uma nova fase da evolução da sociedade e do Estado. O primeiro caso corresponde à compreensão das teorias de campo tratadas no livro como a emergência da teoria funcional da causalidade e essa como expressão do desenvolvimento da sociologia em sua relação com o desenvolvimento da sociedade brasileira (vale lembrar que as teorias desse caráter metodológico bem como o próprio Mário Lins serão criticados pelo autor justamente por seu caráter universalista). O segundo caso leva o autor a uma atitude comparativa com relação ao processo de racionalização do trabalho ocorrido nos Estados Unidos que fundamenta sua crítica aos obstáculos encontrados pelo processo no Brasil.

12 Nos anos 40, Guerreiro Ramos parece já enfatizar a dimensão econômica na definição de planificação social, pois estabelece como os principia media fundamentais da época "atual" que deveriam ser resguardados: a "democracia econômica" (bem-estar material) e a "ética de responsabilidade" (convivência pacífica entre os diferentes "estilos de pensamento"). RAMOS, 1946c). Apesar de Guerreiro Ramos trabalhar com o diagnóstico da alteração da psicologia coletiva como fator decorrente do processo de industrialização, é sobre a intensificação desse último e suas implicações diretas que repousa sua definição de desenvolvimento.
}

Temáticas, Campinas, 14(27/28):157-185, jan./dez. 2006 
sociológico, como já foi dito, e de adequação das pesquisas e seus resultados à fase de desenvolvimento nacional.

$\mathrm{Na}$ direção de criar as bases de uma Sociologia Nacional, Guerreiro Ramos formula, no final dos anos 50, uma proposta metodológica e uma série de leis que deveriam ser seguidas pelos sociólogos brasileiros. Segundo ele, a Redução Sociológica seria a expressão da consciência crítica que se teria desenvolvido na sociedade brasileira a partir dos anos 50. O sociólogo define essa consciência crítica como a capacidade de uma sociedade em se autodeterminar, de se tornar sujeito histórico. Assim, no âmbito da Sociologia ela corresponde a uma atitude metódica que permitiria ao analista separar os fatores históricos dos conceitos (sua funcionalidade em relação ao contexto de onde provieram) e apreender sua essência, ou seus determinantes. Para ele, essa atitude teria grande valor nos países periféricos, pois, neles, haveria a necessidade de usufruir de forma crítica os produtos científicos de países avançados. Por esse motivo o autor se vê na necessidade de distinguir o que denomina de transplantações predatórias e transplantações acelerativas $^{13}$ e o que compreende como universalidade e particularidade na Sociologia ${ }^{14}$.

Essas diferentes formas de conceber os padrões científicos não apenas embasam as propostas metodológicas dos dois autores como, também, dão margem a diferentes concepções de desenvolvimento que são perceptíveis na definição das condições e pré-requisitos para a efetivação desse processo.

\footnotetext{
${ }^{13}$ As primeiras seriam aquelas que comprometeriam a renda nacional, não proporcionando soluções condizentes à fase de desenvolvimento do país, capitalização e nem reserva de divisas fundamentais ao desenvolvimento econômico. As transplantações acelerativas, ao contrário, seriam aquelas capazes de intensificar o processo de capitalização e de desenvolvimento, sendo, portanto, fundamental para esse processo. Nota-se que, além da argumentação sobre as transplantações predatórias e acelerativas mostrarem-se consideravelmente próximas às teses da CEPAL, o próprio autor se refere a essa instituição como empenhada nessa questão. Aqui, se revela também certo primado da economia na definição das medidas para o desenvolvimento.

${ }^{14}$ Para ele, o primeiro aspecto seria reservado aos enunciados gerais enquanto o segundo aos condicionantes histórico-sociais.
} 


\section{Desenvolvimento nacional: duAs concepções}

A concepção de desenvolvimento utilizada por Florestan Fernandes está diretamente relacionada com as acepções de mudança cultural espontânea e mudança cultural provocada ${ }^{15}$. No primeiro caso, o desenvolvimento social aparece na medida em que se formam, na sociedade brasileira, as condições de emergência de um novo "estilo de pensamento" (MANNHEIM, 1981), que permitiria aos indivíduos a capacidade de escolha racional dos fins imediatos de suas ações de maneira que elas não seriam mais orientadas pelos costumes e pela tradição. A mudança cultural provocada, por sua vez coloca a intensificação dessa capacidade de tal forma que os indivíduos adquiririam o controle racional da própria mudança social e sobre a própria organização da sociedade.

Nesse sentido, a análise que Florestan Fernandes realiza sobre a realidade nacional procura definir os obstáculos ao desenvolvimento brasileiro a partir dos fatores que impedem a expansão dos valores "racionais" e "democráticos", e as tendências de desenvolvimento com base nos indicativos da presença desses valores. Isso significa, como já foi indicado anteriormente, a análise da forma de manifestação dos padrões de desenvolvimento condizentes com a moderna civilização ocidental. Assim, os elementos desencadeados com a abolição da escravatura e que permitiram a passagem da Ordem Social Tradicional para

a Ordem

Social Moderna, ou Capitalista, chegariam aos anos 50 caracterizando essa situação como a de mudança social espontânea constituindo uma condição na qual se poderiam identificar tendências de desenvolvimento rumo ao que o autor define como Ordem Social Planificada. Ou seja, para o sociólogo, tratava-se de uma situação em que se podiam encontrar indícios do surgimento de técnicas de controle social ${ }^{16}$ que poderiam, e mais ainda, deveriam ser canalizadas para a consolidação de

${ }^{15}$ A sistematização dessa discussão pode ser encontrada de maneira explícita, por exemplo, no texto "A ciência aplicada e a educação como fatores de mudança cultural provocada" de 1958 no qual o autor procura definir a importância da ciência e da educação na passagem do primeiro ao segundo tipo de mudança social (FERNANDES, 1960). 
uma sociedade organizada democraticamente. Os obstáculos, por sua vez, correspondiam à permanência de valores sociais tradicionais no comportamento dos indivíduos. Sendo contraditória com aqueles valores modernos, tal permanência constituía, para o autor, a fonte de um descompasso característico da sociedade brasileira, naquele momento, ou seja, o atraso da esfera moral em relação ao desenvolvimento material da sociedade.

É a partir desse ponto de vista que Florestan Fernandes se posiciona para analisar a situação do país no final dos anos 50, ou seja, após a experiência do desenvolvimentismo de Juscelino Kubitschek. Nesse momento, o sociólogo procura recolocar seus critérios de definição de desenvolvimento a partir da situação nacional e das discussões que dela resultam. $\mathrm{O}$ argumento do autor consiste na rejeição das análises que tratavam isoladamente os fatores considerados como indicativos do desenvolvimento nacional, em especial a industrialização. Para ele, os resultados desse tipo de análise não davam conta da condição de "desenvolvimento" da sociedade como um todo, deixando de lado a dimensão social da industrialização sem a qual o processo não existiria. A análise dessa dimensão conjuntamente às interpretações sobre a esfera econômica, possibilitaria, segundo o sociólogo paulista, a superação de um tipo de reflexão limitada por critérios universais de interpretação do desenvolvimento, incorporando a especificidade das condições societárias para a compreensão desse fenômeno. É, aqui, que entra a especificidade da situação dos países subdesenvolvidos na definição de dois aspectos

freqüentemente discutidos por analistas do desenvolvimento social no momento: as "atitudes e motivações favoráveis ao desenvolvimento". Nesse sentido, para Florestan Fernandes, alguns fatores que estariam sendo apontados como "favoráveis" ao desenvolvimento muitas vezes correspondiam a verdadeiros obstáculos ao fortalecimento do capitalismo nacional.

\footnotetext{
${ }^{16}$ Para Mannheim, tais técnicas sociais correspondem ao "conjunto dos métodos que visam a influenciar o comportamento humano e que, quando nas mãos do Governo, agem como meios especialmente poderosos de controle social" (MANNHEIM, 1973).
} 
Assim, Florestan Fernandes questiona, nesse momento, a capacidade intelectual e moral da sociedade brasileira em enfrentar seus próprios dilemas. O critério de que se utiliza para a análise dessa capacidade é o alcance do raciocínio de caráter racional no comportamento dos indivíduos. Utilizando-se das análises de Weber e de Parsons (MANNHEIM, 1981), o sociólogo procura demonstrar como, no Brasil, ao contrário do que ocorreu na Europa, o aparecimento de técnicas de controle racional nas ações dos indivíduos não se deu conjuntamente ao estabelecimento da industrialização. Por isso, apesar dessa emergência se concretizar, mesmo que tardiamente, acaba sendo limitada pela permanência de fatores irracionais constituindo verdadeiros obstáculos que impedem o que considera, de fato, como desenvolvimento nacional. Essa linha de argumentação coloca a necessidade de soluções particulares aos problemas de desenvolvimento dos países latino-americanos, abrindo espaço para o diálogo com os defensores de medidas universais para a solução dos obstáculos do desenvolvimento, ao mesmo tempo em que fundamenta a defesa de determinado projeto de desenvolvimento. Vale destacar que Guerreiro Ramos também procura fazer a crítica aos critérios exclusivamente econômicos na definição do desenvolvimentismo de Juscelino Kubitscheck. Mas, neste caso, a crítica está focada de maneira geral nos limites à autonomia nacional impostas pelos critérios internacionais de definição de desenvolvimento e na incapacidade do Estado em promover a emancipação econômica do país.

Em se tratando da concepção de desenvolvimento que Guerreiro Ramos utiliza nos trabalhados dos anos 50 e início dos anos 60, pode-se destacar a centralidade da concepção de fase que é justamente o que, para ele, define a particularidade nacional. Como já foi dito, a sociedade brasileira é interpretada como estando em uma fase de transição. Os anos 50 são vistos como um marco através do qual o Brasil teria atingido certo grau de avanço do capitalismo que teria criado as condições materiais necessárias para uma mudança estrutural da sociedade brasileira ${ }^{17}$. Essa

$17 \mathrm{O}$ momento de transição que o autor caracteriza na superação da fase de predominância agrária, da Lei da Complementaridade, traria consigo algumas tendências tais como o centripedis- 
mudança

estrutural teria como alvo a emancipação do país, sua autodeterminação. Contudo, tendo em vista essa fase de transição, Guerreiro Ramos identifica em Cartilha Brasileira do Aprendiz de Sociólogo um estado de crise oriunda da tensão entre complementaridade e autodeterminação, ou seja, da coexistência de obstáculos e tendências no sentido da emancipação nacional ${ }^{18}$.

Ao refletir, especificamente, sobre os critérios de definição de desenvolvimento, procurando questionar os critérios em voga no plano internacional, Guerreiro Ramos afirma que a Sociologia Comparada deveria apenas ser aplicada sobre as tendências de desenvolvimento apresentadas pela sociedade, enquanto caberia à Sociologia Diferencial a capacidade de apreender a particularidade histórica e, com isso, definir as medidas a serem tomadas rumo ao desenvolvimento nacional. Dessa forma, propõe tais critérios de definição de desenvolvimento: 1) distribuição da mão-de-

mo da economia brasileira, o aparecimento da consciência crítica (da consciência da situação colonial, em vários setores da sociedade), o nacionalismo, a emergência do povo como força política, as bases de fundação da nação, a defesa da intervenção do Estado na economia por alguns capitalistas brasileiros, o surgimento das condições para uma Sociologia Nacional.

${ }^{18} \mathrm{O}$ diagnóstico dessa coexistência e da situação de crise da sociedade brasileira dos anos 50 também pode ser identificada nos trabalhos de Florestan Fernandes, mas, aqui, a tensão que os estrutura é, como já foi destacado, aquela entre o que o autor define como Ordem Social Tradicional e Ordem Social Moderna. Contudo, essa dimensão cultural também pode ser identificada nos textos Pauperismo e Medicina Popular e O Problema da Mortalidade Infantil no Brasil (1951) nos quais o autor apresenta uma visão de cultura popular como de permanência do comportamento não racional, tal como nos trabalhos de Florestan Fernandes sobre o folclore (mesmo se se levar em consideração o caráter crítico a partir do qual esse autor procura se colocar no tocante à participação da cultura popular no processo de mudança social) e em seu projeto educacional de caráter iluminista. Além daqueles trabalhos de Guerreiro Ramos essa concepção de "atraso" da cultura popular pode ser observada na $6^{a}$. Recomendação que o autor formula:'É francamente desaconselhável que o trabalho sociológico, direta ou indiretamente, contribua para a persistência, nas nações latino-americanas, de estilos de comportamento de caráter pré-letrado. Ao contrário, no que concerne às populações indígenas ou afro-americanas, os sociólogos devem aplicar-se no estudo e na proposição de mecanismos de integração social que apressem a incorporação desses contingentes humanos na atual estrutura econômica e cultural dos países latino-americanos". Mas, vale dizer que essa visão não aparece como central na definição de crise como em Florestan Fernandes (RAMOS, 1995, p.106). 
obra pelos ramos da atividade produtiva; 2) renda nacional per capita; 3) consumo per capita de energia; 4) urbanização; 5) produção industrial.

Com o aproximar dos anos 60, esses critérios de avaliação do desenvolvimento levam o sociólogo a caracterizar uma fase revolucionária a partir do diagnóstico da intensificação daquelas tendências e a identificação do povo $^{19}$ como força política capaz de promover a emancipação do país. Esse diagnóstico da emergência da consciência e capacidade políticas do povo tem como base certa compreensão dos resultados do desenvolvimento do capitalismo nacional. Com base nesse diagnóstico, Guerreiro Ramos defende que o Brasil estaria vivendo uma situação revolucionária na qual se poderiam encontrar tendências e obstáculos. As tendências se apresentariam no desenvolvimento econômico e social alcançado pelo país até o momento, o que definiria as condições objetivas. Os obstáculos, por sua vez, estariam relacionados à falta de condições subjetivas na liderança política do movimento emancipador. Por isso, a crítica que o autor realiza à situação política do país caracterizada, segundo ele, pela crise de representatividade e pela crise de poder e ao Plano de Metas de JK. Isso somado à identificação da iminência da Revolução Brasileira, apesar da ênfase que o autor procura dar, no momento, para a necessidade de revisão crítica do marxismo.

É interessante notar como o movimento da sociedade brasileira leva os autores a reverem algumas de suas teses sem, contudo, se desfazer de suas características essenciais. É o momento de revisão do desenvolvimentismo de JK, dada a crise econômica, política e social na qual o país adentrava, e do desencadeamento de tensões sociais que dão força ao discurso marxista. Tais fatores são absorvidos pelos autores levando-os a reforçar conceitos como classe, conflito social, revolução social, e a questionar as teses desenvolvimentistas. De maneira específica, podese dizer que Florestan Fernandes, procurando focalizar a crítica ao

\footnotetext{
${ }^{19}$ O povo, nesse caso, é compreendido como uma categoria que extrapola as classes e outros grupos de forma a ser composto não apenas de membros das classes trabalhadoras (que seriam a maioria), mas de todos os grupos empenhados num projeto de emancipação nacional que corresponderia aos interesses gerais da "comunidade brasileira" (RAMOS, 1960, p.247). Nesse sentido, a situação proletária dos países periféricos se sobrepõe a dos trabalhadores nacionais.
} 
desenvolvimentismo, destaca a particularidade do processo de desenvolvimento nacional como forma de chamar a atenção aos resultados obtidos pela concentração do projeto de desenvolvimento na esfera econômica e nos interesses das classes dominantes. Ao mesmo tempo, esse diagnóstico leva o autor a enfatizar também essa área nos alvos das pesquisas fundamentais para a condução do desenvolvimento nacional. Trata-se de uma tentativa de conferir uma abordagem sociológica à Economia no sentido de permitir a essa área a criação de condições de desenvolvimento para o Planejamento Democrático ${ }^{20}$. Contudo, continua a centrar o teor de suas análises nos critérios funcionais fundamentados no período anterior, sobretudo no que dizem respeito ao papel da sociologia e ao planejamento democrático, mas a partir da definição do momento como Revolução Social. Guerreiro Ramos, por sua vez, recorre à política para a crítica às teses desenvolvimentistas. Nesse sentido, o diagnóstico da emergência do povo abre caminho para o autor definir uma situação de crise política em função da não canalização dos interesses populares na política governamental e da negligência do governo em relação aos interesses gerais da nação. Assim, o autor incorpora a temática da democracia política como forma de se fazer resguardar os interesses nacionais. Não obstante, as concepções de conflito social e de revolução social não chegam a atingir suas últimas conseqüências de maneira que permanece a preocupação com os interesses da nação, sobretudo os econômicos, sobre os de classes e, com isso, ancoram um projeto reformista de desenvolvimento social, tal como em Florestan Fernandes. Essa forma de condução da problemática do desenvolvimento nacional, ou seja, o que define a solução da tensão sociedade velha $X$ sociedade nova, fundamenta o que se pode chamar de formulação, pelos dois autores, de um projeto nacional.

\footnotetext{
${ }^{20}$ Essa é a justificativa dos projetos A Empresa Industrial em São Paulo e Economia e Sociedade no Brasil: análise sociológica do subdesenvolvimento nos quais o papel do empresariado, do Estado e do trabalhador no desenvolvimento nacional é tomado como objeto de estudo.
} 


\section{Duas idéias de Brasil Moderno}

É a partir da concepção de desenvolvimento enquanto passagem do estágio de mudança social espontânea para o de mudança cultural provocada que Florestan defende seu projeto de desenvolvimento nacional. Esse projeto é fortemente influenciado pela formulação do projeto de Planejamento Democrático de Karl Mannheim ${ }^{21}$ e será o eixo de suas propostas de desenvolvimento nacional. Assim, o sociólogo propõe o que define como Ordem Social Planificada, ou seja, uma forma de organização social na qual a democracia social é definida a partir da capacidade de todos os indivíduos em determinar racionalmente os destinos da sociedade. Nesse sentido, essa forma de organização social somente poderia se concretizar a partir da expansão do que compreende como "racionalização" a todas as esferas da vida social. Não é a toa que o principal alvo sobre o qual o autor se direciona consiste no papel da educação no processo de desenvolvimento social. É essa instância o centro propagador dos princípios "racionais" de comportamento social ${ }^{22}$.

Como já foi dito, no final dos anos 50 , já com a possibilidade de refletir sobre os resultados do projeto de desenvolvimento implantado por Juscelino Kubitschek através do Plano de Metas, Florestan Fernandes reforça esse projeto de caráter cultural através de uma crítica à centralidade adquirida pela esfera econômica nos rumos tomados pela política nacional. Por outro lado, a economia passa a ser uma dimensão destacada pelo autor como condição para o desenvolvimento. Com isso, o sociólogo passa a definir como alvos centrais para a contribuição do conhecimento científico ao desenvolvimento da sociedade brasileira as esferas econômica e social ${ }^{23}$. Assim, mesmo procurando enfatizar essas

21 “O planejamento para a liberdade não significa a imposição de uma forma definida de individualidade, mas tendo o conhecimento e a experiência de decidir que tipo de educação, que tipo de grupos sociais e que tipo de situações proporcionam a melhor oportunidade de fomentar a iniciativa, o desejo de formar o próprio caráter e de decidir o próprio destino". (MANNHEIM, 1962, p.274)

22 "A ciência aplicada e a educação como fatores de mudança cultural provocada" (FERNANDES, 1960); "Existe uma crise da democracia no Brasil?" (FERNANDES, 1979a) ${ }^{23}$ Com isso, pode-se identificar os projetos A Empresa Industrial em São Paulo e Economia e Sociedade no Brasil: análise sociologica do subdesenvolvimento no CESIT (Centro de Sociologia Indus- 
duas dimensões e absorvendo, em certa medida, a temática das classes sociais e da revolução social ${ }^{24}$ a compreensão do processo de mudança, ou de revolução social, se dá em termos culturais.

$\mathrm{Na}$ argumentação de Florestan Fernandes, a realização do projeto de controle racional, planejado da realidade social tem como pressupostos a intervenção do conhecimento científico no processo social e a superação dos descompassos entre a ordem material e moral da sociedade. Esse ponto de partida leva o autor a enfrentar os dilemas nacionais que envolvem diretamente tais pressupostos e a definir os focos de intervenção da sociologia para o desenvolvimento nacional. As mudanças de base propostas por Florestan Fernandes correspondem, então, à atuação da educação escolar ${ }^{25}$ e da propaganda, para estimular a capacidade de escolha racional dos indivíduos; ao estabelecimento de veículos de canalização do comportamento coletivo, para viabilizar aquelas escolhas; ao desenvolvimento de mecanismos de controle do poder institucionalizado, para impedir a manipulação dos interesses coletivos; ao desenvolvimento da ciência, da tecnologia e da educação, para garantir o uso e a criação das técnicas sociais necessárias para uma sociedade planificada; e, por fim, ao desenvolvimento de meios democráticos de mudança social, para garantir o equilíbrio dinâmico da sociedade (FERNANDES, 1976).

Nos textos de Florestan Fernandes, datados do final dos anos 50 e início dos anos 60, a absorção do contexto de fortalecimento do discurso marxista é perceptível pela dimensão que passam a adquirir algumas

categoriais tais como as de classes populares, classes dominantes, ideologia; revolução, e poder. Essas categorias são instrumentos para o sociólogo tematizar: o jogo de interesses entre as classes sociais; o desenvolvimentismo como ideologia e alienação; a revolução social do

trial e do Trabalho) como concretização das propostas de papel da sociologia e do desenvolvimento nacional formuladas teoricamente nos anos 50 (ROMÃO, 2003)

${ }^{24}$ Como sugere o próprio título do livro A Sociologia Numa Era de Revolução Social (1962)

${ }^{25}$ Vale lembrar que no final dos anos 50 Florestan Fernandes participa da Campanha de Defesa da Escola Pública (MAZZA, 1997; ROMÃO, 2003) 
momento e; a demagogia. Assim, tendo em vista o projeto de planejamento democrático e a influência das questões levantadas por esse discurso, Florestan Fernandes chega à crítica às classes dominantes, no que se refere à defesa de interesses particularistas, à incapacidade de intervenção do Estado no desenvolvimento social e à imaturidade das classes populares. Esse é um momento no qual o autor identifica um estado de Revolução Social. Esse tipo de definição é pautado tanto na identificação de reações societárias que buscam participação no processo político, quanto na compreensão do projeto de Planejamento Democrático como uma possibilidade real.

Tendo em vista um projeto de desenvolvimento formulado segundo a lógica de uma Ordem Social Planificada, vale ressaltar a maneira pela qual Florestan Fernandes procura chamar a atenção das classes dominantes para a possibilidade de uma mudança de caráter conciliatório, tal como Mannheim em seu projeto de reconstrução social. Trata-se de um viés reformista que se sobrepõe de fato à possibilidade de uma revolução no sentido marxista que, como destaca o próprio autor, se coloca nos movimentos sociais de esquerda que eclodem entre o final dos anos 50 e início dos anos 60. Assim, partindo da crítica ao conservadorismo brasileiro que, segundo ele, não se preocupa em "salvar a herança social por meio da renovação", formula uma espécie de "chantagem" às classes dominantes para que optem pelos meios democráticos e pacíficos da Ordem Social Planificada (FERNANDES, 1976a, p.211).

Contudo, essa incorporação da temática dos movimentos sociais e da compreensão dos seus objetivos confere uma dimensão importante para a argumentação de Florestan Fernandes, nesse período. Se, em meados dos anos 50, a concretização do projeto uma Ordem Social Democrática pressupunha primeiro o desenvolvimento intelectual e moral do homem comum para a nova ordem social, no final dos anos 50 e inícios dos 60 a participação das massas populares passa a ser uma necessidade premente para o sociólogo paulista. Não há como o sociólogo deixar de incorporar os movimentos sociais na reflexão, pois eles marcam fortemente sua presença na realidade social analisada. É 
claro que o projeto de Planejamento Democrático tinha como base a participação das massas, mas nesse momento elas aparecem como um agente com considerável força no processo de mudança social. Por isso, mesmo defendendo o papel do intelectual e das elites para o estabelecimento da nova ordem social, o sociólogo não pode deixar de dar maior ênfase à questão democrática. Essa questão aparece como condição e não como conseqüiência do Planejamento Democrático, mas, como já foi visto, ainda nos marcos de um projeto de caráter conciliatório $^{26}$.

De maneira geral, as propostas de Guerreiro Ramos têm em vista um projeto de desenvolvimento econômico que pode ser observado tanto na definição do que considera como fase de desenvolvimento e, portando da capacidade da dimensão econômica em impulsionar a mudança estrutural na sociedade, quanto na compreensão do projeto de desenvolvimento industrial como forma de realização dos interesses da sociedade brasileira como um todo naquele momento. Isso define uma distinção da concepção de democracia que os dois autores buscam como solução para o desenvolvimento do país, sendo uma mais próxima ao controle do processo de emancipação nacional e, outra, centrada na capacidade de controle racional da sociedade. Assim, mesmo tendo no horizonte um projeto de construção da nação brasileira que envolveria um projeto amplo de emancipação, o alvo central do projeto nacional de Guerreiro Ramos consiste, antes, no desenvolvimento industrial, pois, como já foi visto, é ele quem criaria as bases para a passagem para uma nova fase da realidade nacional. A centralidade da dimensão econômica na definição das medidas pragmáticas para o desenvolvimento nacional pode ser observada em vários aspectos dos trabalhos do autor, aparecendo de antemão nas recomendações aos sociólogos em Cartilha

${ }^{26}$ A questão democrática é o foco do texto de Florestan Fernandes, "Existe uma crise da democracia no Brasil?” de 1954. Nesse texto, mesmo o autor chamando a atenção para a dimensão histórica e da do conflito social, a perspectiva funcionalista se mostra dominantes, tanto na identificação dos problemas sociais quanto na definição do projeto de Planejamento Democrático. Nesse sentido, a crítica aos partidos e ao governo que o autor realiza está centralizada na incapacidade dessas duas instâncias em desempenhar e estimular os fatores educativos no sentido de uma Ordem Social Planejada. 
Brasileira do Aprendiz de Sociólogo (1954). Além desse fator específico à esfera intelectual, essa perspectiva pode-se ser identificada: a) na definição de crise brasileira, apresentada em 1956, como resultado das transformações materiais pelas quais o país estaria passando; b) na convocação de uma classe dirigente para a condução, para o planejamento, do desenvolvimento econômico; c) na defesa do Estado como sujeito do desenvolvimento econômico; e) na crítica à inadequação das instituições brasileiras em relação à fase de desenvolvimento do país, ou seja, às tendências de emancipação nacional; f) na definição dos alvos da Segurança Nacional centrados na salvaguarda dos interesses econômicos nacionais; g) na crítica à política externa brasileira que deveria ser condizente com uma "nova etapa de convivência internacional".

No ano de 1958, Guerreiro Ramos realiza uma revisão crítica do Plano de Metas formulado e aplicado pelo Governo Kubitschek. Sua construção analítica parte de uma noção de racionalidade econômica ${ }^{27}$ que fundamenta o elo entre racionalidade e desenvolvimento nacional, tornando irracionais as medidas contrárias à "melhoria genérica das condições de vida da população" (RAMOS, 1960). Por definição, a racionalidade da programação econômica poderia ser avaliada a partir da forma de aplicação dos excedentes de produção e essa deveria baseada em premissas ideológicas vinculadas aos interesses gerais da nação.

Pode-se perceber uma noção de democracia relacionada à capacidade de controle do planejamento econômico pelas massas no sentido da consecução da emancipação nacional e, conseqüentemente, de metas de bem-estar material. Assim, tendo em vista um projeto de desenvolvimento econômico, Guerreiro Ramos convoca a política como catalisadora desse processo ${ }^{28}$. Dessa forma defende a superação da crise partidária como forma de restabelecimento da representatividade que permitiria o controle das ações do governo para a efetivação dos interesses

\footnotetext{
27 Isso em contraposição à idéia de racionalidade substancial de Mannheim (RAMOS, 1960, p.186).

${ }^{28}$ Vale lembrar que Guerreiro Ramos se candidata no início dos anos 60 à deputado federal pelo P'TB.
} 
gerais da nação ${ }^{29}$. Guerreiro Ramos define algumas forças políticas que potencialmente poderiam executar tal tarefa enquanto isso não se realizasse: o Congresso, as Forças Armadas, os técnicos do Serviço Público, os setores do meio Empresarial, e as associações de trabalhadores. Dentre as respectivas atribuições, o autor destaca a ação dos empresários industriais brasileiros na realização da Revolução Brasileira enquanto Revolução Burguesa, diagnosticando, ao mesmo tempo a falta de coerência e de consciência de seu papel, fator esse compartilhado por Florestan Fernandes.

Tal como o sociólogo paulista, no final dos anos 50 e início dos anos 60, Guerreiro Ramos define uma situação revolucionária brasileira, ou seja, identifica as tendências de uma Revolução Nacional a partir do reconhecimento de condições materiais, em vista do nível alcançado pelo desenvolvimento industrial brasileiro, e de condições sociais, baseado no diagnóstico da emergência do povo como expressão do surgimento de uma consciência dos interesses nacionais. O povo torna-se, na argumentação, o principal ator do processo de Revolução Nacional, tendência que também pode ser percebida na argumentação de Florestan Fernandes. Dessa forma, Guerreiro Ramos retira um papel que, por ineficiência, teria deixado de ser realizado pela burguesia industrial e o atribui ao

povo. Para isso, contudo, o autor aposta numa reforma política a partir da qual o povo seria incorporado ao Estado tomando a direção do processo de emancipação nacional. Como, para ele, a categoria povo, no caso da Revolução Nacional, transcenderia os interesses das classes sociais, os interesses prevalecentes no seu projeto nacional seriam os interesses gerais da nação. Nesse sentido, a situação proletária dos países periféricos se sobrepõe à dos trabalhadores nacionais, apesar de o autor colocá-los enquanto maioria na composição do povo. Não é à toa que tal visão reformista aparece na definição dos princípios do trabalhador brasileiro nos quais destaca a definição desses enquanto sócios do desenvolvimento nacional, dos seus direitos de participar do Governo, da necessidade de

\footnotetext{
${ }^{29}$ Segundo Guerreiro Ramos, quando ocorre a concretização dos interesses de um só grupo, corre-se o risco de uma ação revolucionária (p. 213).
} 
controle ideológico dos programadores econômicos (que deveriam defender os interesses gerais), a primazia dos interesses gerais sobre os sectários e a defesa das soluções nacionais aos problemas brasileiros. Assim, o autor também definiria um teor reformista para as reivindicações dos trabalhadores naquele momento ${ }^{30}$.

Isso delimita os moldes reformistas da Revolução Brasileira defendida intensamente pelo autor, não só neste como em outros livros publicados no momento a despeito de qualquer nuance que o autor procure concretizar. É o caso, por exemplo do livro $A$ Crise do Poder no Brasil (1961) no qual pode-se identificar um diálogo direto com a esquerda brasileira através da inserção da questão do conflito social. Contudo, o autor recoloca a reforma institucional como uma forma de assimilação dos diferentes interesses, dando mais uma vez uma solução reformista para o conflito social em iminência e definindo as possibilidades concretas de resolução da questão: a ditadura e a revolução. Como se pode perceber, a questão do conflito parece, a princípio, redefinir o projeto revolucionário do autor, mas em última instância esse aparece ainda enquanto reforma político-institucional a partir da qual deveriam prevalecer os interesses da Revolução Nacional segundo os termos já citados. Dessa forma, ao defender a efetiva capacidade de representação política dos partidos políticos, Guerreiro Ramos coloca a necessidade de organização partidária das aspirações populares para a conquista de suas exigências no governo ${ }^{31}$.

\footnotetext{
30 Guerreiro Ramos faz uma identificação entre o Nacionalismo e o Socialismo (RAMOS, 1960).

31 O autor, aqui, propõe uma reforma administrativa por parte do Governo Jânio Quadros (RAMOS, 1961, p.100-102). Em contrapartida, em Mito e Verdade da Revolução Brasileira (1963) o autor se relaciona ambiguamente com a idéia de organização partidária. De um lado, ao procurar definir a Revolução Nacional em termos não marxista-leninistas e, com isso, buscar dar uma nova orientação teórica à esquerda nacional, Guerreiro Ramos incide uma crítica sobre o papel do Partido na Revolução Russa, ou seja, sobre a incorporação do socialismo nos partidos políticos. Por outro lado, o autor defende em outros momentos a importância da organização na ação política. O Socialismo seria uma nova forma de organização da sociedade, e também político-partidário, na qual prevaleceriam os interesses dos trabalhadores. Essa parece ser a forma pela qual se daria a emancipação dos países periféricos já que privilegia o autor, em dado momento, a decisão política em detrimento do que considera como determinismo econômico (p.42-45). Contudo, em outro momento, ele destaca a necessidade de desenvolvi-
} 
$\mathrm{Na}$ medida em que a análise se volta para a realidade brasileira, ela parece se associar a um projeto de emancipação nacional mais próximo de uma Revolução Burguesa. Esse ainda é o teor da definição de Revolução do autor, mesmo que a considere como Socialista. Apesar de não explicitamente, o diagnóstico do desenvolvimento das forças produtivas nacionais parece dar o sentido da Revolução Brasileira para a definição da possibilidade de ajustamento do modelo marxista de revolução. Por isso, a possibilidade primeira de uma Revolução Brasileira enquanto "reorganização institucional".

Pode-se perceber que, nas diferentes nuances da argumentação nesses trabalhos, há uma tentativa do autor de se situar na esquerda e em determinado tipo de nacionalismo. Por isso a necessidade de desconstruir algumas teses da esquerda brasileira, em especial as do Partido Comunista, e de outras vertentes nacionalistas. Isso procurando justificar seu projeto nacional enquanto revolucionário e absorvendo de modo característico a terminologia da esquerda. Além disso, o autor se refere também a um projeto existencial no qual o homem adquiriria o controle da "organização" e não o contrário. Esse seria um caso de desenvolvimento social de um tipo superior de sociedade em moldes democráticos $^{32}$. Contudo, o diálogo com as teses desenvolvimentistas continua a aparecer e, ainda, como forma de solucionar as questões sociais.

Os movimentos da constituição do capitalismo ou da modernização brasileiros removeram conjuntamente a história das idéias e isso é perceptível na maneira pela qual os dois autores enfrentaram os problemas relacionados a esses processos. Nesse sentido, ambos

mento das forças produtivas para a realização da "verdadeira revolução", o que definiria a especificidade da revolução nesses países. Essa ambigüidade aparece na medida em que o autor cita como exemplo a especificidade das revoluções africanas, a chinesa e mesmo a russa, mostrando como a decisão política pode prevalecer num processo revolucionário.

32 Em Mito e Verdade da Revolução Brasileira (1953), Guerreiro Ramos realiza um diagnóstico estreitamente relacionado à esfera cultural que daria suporte à sua proposta de Revolução $\mathrm{Na}$ cional. Trata-se, segundo ele, do aparecimento da atitude parentética que consistiria na capacidade de reflexão do homem sobre os condicionantes sociais e de realização do poder do mesmo sobre a sociedade. Sendo assim, a democratização dessa atitude levaria ao "período da história consciente do homem" (p.146). 
procuraram definir os patamares metodológicos em função da identificação do "problemas sociais" e das possibilidades de superação dos mesmos. Separando-se no encaminhamento dessas questões no transcorrer dos anos 50, encontraram-se na onda dos movimentos revisionistas. $\mathrm{O}$ enfrentamento desse novo clima político e intelectual leva Florestan Fernandes a dar maior importância à dimensão econômica no projeto de Planejamento Democrático e Guerreiro Ramos a se voltar para a temática da democracia política, sustentando, inclusive, a democratização da cultura. Contudo, a despeito da incorporação das categorias marxistas e da reflexão alcançada a partir delas, pode-se ainda, reconhecer a manutenção dos projetos formulados na década anterior e que tendiam, de um lado para a educação e para a mudança cultural na sociedade e, de outro, para a realização da emancipação nacional e de um estado de bem-estar material. Se os acontecimentos relativos ao processo de desenvolvimento nacional e às expectativas otimistas das possibilidades do Brasil se tornar uma nação moderna aproximam os dois sociólogos, a forma e o conteúdo de suas formulações expressam duas maneiras distintas de construção de um projeto para o país, constituindo dois caminhos e duas Idéias de Brasil Moderno.

Aвsтract: This work has as objective to demonstrate the way for which two Brazilian sociologists, Florestan Fernandes and Guerreiro Ramos, in the years 50 and beginning 60 , constructed two conceptions of Modern Brazil through its theoretical pressupositions, understood as form of construction of a Brazilian Sociology. Of this form, the work searchs to associate this attempt of construction of the foundations of a Brazilian Sociology with the proper process of national development and, mainly, with the formulation of a National Project.

Keywords: Florestan Fernandes, Guerreiro Ramos, brazilian sociology, national development

\section{ReferênCias Bibliográficas}


FERNANDES, Florestan. Ensaios de sociologia geral e aplicada. São Paulo: Pioneira, 1960.

- Fundamentos empiricos da explicação sociológica. 2a. edição, Rio de Janeiro: Zahar, 1972 (a primeira edição do livro é de 1967)

- A sociologia numa era de revolução social. $2^{a}$ edição, Rio de Janeiro: Zahar, 1976 (a primeira edição do livro é de1962).

- Mudanças sociais no Brasil. 3a. edição, São Paulo: DIFEL, 1979a (a primeira edição do livro é de 1960)

- Folclore e mudança social na cidade de São Paulo. 2a . edição, Petrópolis: Vozes, 1979b (a primeira edição do livro é de 1961)

- A sociologia no Brasil. (2a . edição), Petrópolis, Vozes, 1980 (a primeira edição do livro é de 1977)

IANNI, Octavio. A idéia de Brasil Moderno. São Paulo, Brasiliense, 2004.

RAMOS, Alberto Guerreiro. O problema da mortalidade infantil no Brasil. Sociologia, São Paulo, 13 (3), p.1-43, 1951a.

- O Processo da Sociologia no Brasil (esquema de uma história das idéias). Rio de Janeiro, s/ ed., 1953.

. "A problemática da realidade brasileira". In: Introdução aos problemas do Brasil. Rio de Janeiro: ISEB, 1956.

- Condições Sociais do Poder Nacional. Rio de Janeiro: ISEB, 1957a.

- Ideologias e Segurança Nacional. Rio de Janeiro: ISEB, $1957 \mathrm{~b}$.

- A Redução Sociológica (introdução ao estudo da razão sociológica). Rio de Janeiro: ISEB, 1958.

- Estrutura atual e perspectivas da sociedade brasileira. Revista Brasiliense, São Paulo, 18, p.48-59, 1958.

- O Problema Nacional do Brasil. $2^{a}$ edição, Rio de Janeiro: Saga, 1960.

- A Crise do Poder no Brasil. Rio de Janeiro, Zahar, 1961.

- Mito e Verdade da Revolução Brasileira. Rio de janeiro: Zahar, 1963.

- A Redução Sociológica (introdução ao estudo da razão sociológica). $2^{\mathrm{a}}$ edição, corrigida e aumentada, Rio de Janeiro: Edições Tempo Brasileiro, 1965.

- Introdução Crítica à Sociologia Brasileira. Rio de Janeiro: UFRJ, 1995 (a $1^{a}$. edição é de 1957) 
- Cartilha Brasileira do Aprendiz de Sociólogo. In: RAMOS, Guerreiro. Introdução Crítica à Sociologia Brasileira. Rio de Janeiro, 1995 (a $1^{\text {a }}$. edição é de 1954).

\section{Bibliografia}

ARRUDA, Maria Arminda do Nascimento. Metrópole e Cultura: São Paulo no meio do século XX. Bauru, SP: EDUSC, 2001.

BRANDÃO, Gildo Marçal. A esquerda positiva: as duas almas do Partido Comunista - 1920/1964. São Paulo: Hucitec, 1997.

BAUER, Otto. "A Nação". In: GOPAL, Balakrishnan (org) Um Mapa da Questão. Rio de Janeiro: Contraponto, 2000.

BARIANI JR, Edison. A sociologia no Brasil: uma batalha, duas trajetórias (Florestan Fernandes e Guerreiro Ramos). Araraquara, 2003. Dissertação de Mestrado, FCL-UNESP.

BOURDIEU, Pierre. Economia das trocas simbólicas. São Paulo: Perspectiva, 1982.

GOLDMANN, Lucien. A Sociologia do Romance. Rio de Janeiro: Paz e Terra, 1976.

- "O todo e as partes". In: Dialética e cultura. Rio de Janeiro: Paz e Terra, 1979.

IANNI, Octavio. O colapso do populismo no Brasil. 33. edição, Rio de Janeiro: Civilização Brasileira, 1975.

LESSA, Carlos. 15 anos de política econômica. São Paulo: Brasiliense, 1981.

LUKÁCS, Georg. "Narrar ou descrever?”. IN: Ensaios sobre literatura. Rio de Janeiro: Civilização Brasileira, 1965.

. "A polêmica entre Balzac e Stendhal". IN: Ensaios sobre literatura. Rio de Janeiro: Civilização Brasileira, 1965.

- "Les illusions perdues". IN: Ensaios sobre literatura. Rio de Janeiro: Civilização Brasileira, 1965.

MANNHEIM, Karl. O homem e a sociedade: estudos sobre a estrutura social moderna. Rio de Janeiro: Zahar, 1962.

- Liberdade, poder e planificação democrática. São Paulo: Editora Mestre Jou, 1972. 
- Diagnóstico de nosso tempo. Rio de Janeiro: Zahar, 1973.

- "O pensamento conservador". In: MARTINS, José de Souza (org) Introdução crítica à sociologia rural. São Paulo: HUCITEC, 1981.

- Ideologia e utopia. 4a edição. Rio de Janeiro: Guanabara, 1986.

MAZZA, Débora. A produção sociológica de Florestan Fernandes e a problemática educacional: uma leitura (1941-1964). Campinas, 1997. Tese de Doutorado- IFCH-Unicamp.

MELLO, João Manuel Cardoso de. "Capitalismo Tardio e Sociabilidade Moderna”. In: SCHWARCZ, Lilia Moritz (org.) História da Vida Privada no Brasil. Contrastes da intimidade contemporânea. São Paulo: Companhia das Letras, v.4, 1998.

PÉCAUT, Daniel. Os intelectuais e a politica no Brasil: entre o povo e a nação. São Paulo: Ática, 1990.

OLIVEIRA, Lúcia Lippi. A sociologia do Guerreiro. Rio de Janeiro: UFRJ, 1995.

ROMÃO, Wagner de Melo. A experiência do CESIT: sociologia e politica acadêmica nos anos 1960. São Paulo, Dissertação de Mestrado FFLCH-USP, 2003.

SOARES, Luiz Antonio Alves. A sociologia crítica de Guerreiro Ramos: um estudo sobre um sociólogo polêmico. Rio de Janeiro, Copy \& Arte, 1993.

- Entrevista. In: OLIVEIRA, Lúcia Lippi de. A sociologia do Guerreiro. Rio de Janeiro, UFRJ, 1995.

TOLEDO, Caio. ISEB: fábrica de ideologias. Campinas, Unicamp, 1997. 